\title{
Environmental Factors as Determinants of Severity of SCD in Nigeria
}

\section{Wakama $\mathrm{T}^{1 *}$, Adediran $\mathrm{A}^{2}$ Babadoko $\mathrm{A}^{3}$, Asuquo $\mathrm{M}^{4}$, Kagu $\mathrm{M}^{5}$,} Damulak $\mathrm{D}^{6}$, Ocheni $\mathrm{S}^{7}$ and David $\mathrm{E}^{1}$

${ }^{1}$ Department of Haematology and Blood Transfusion, National Hospital, Nigeria ${ }^{2}$ Department of Haematology and Blood Transfusion, University of Lagos, Nigeria ${ }^{3}$ Department of Haematology and Blood Transfusion, Ahmadu Bello University Teaching Hospital, Nigeria

${ }^{4}$ Department of Haematology, University of Calabar Teaching Hospital, Nigeria

${ }^{5}$ Department of Haematology and Blood Transfusion, University of Maiduguri Teaching Hospital, Nigeria

${ }^{6}$ Department of Haematology and Blood Transfusion, Jos University Teaching Hospital, Nigeria

${ }^{7}$ Department of Haematology and Immunology, University of Nigeria, Nigeria

*Corresponding author: Tamunomieibi Wakama, Department of Haematology and Blood Transfusion, National Hospital, Abuja, Nigeria, Tel: +2348033117247; Email: drttwakama@gmail.com

\section{Abstract}

Sickle cell anaemia (SCA) is a chronic blood disorder characterized by red blood cells that assume an abnormal sickle shape when deoxygenated and may block different areas of the microcirculation causing ischaemia in various organs. This study was carried out to find out the roles of environmental factors in determining the clinical severity of SCA in Nigeria.

Subjects and Methods: This was a multicentre cross-sectional study amongst 261 SCA subjects in seven tertiary health care centres in Nigeria. After obtaining each Institution's ethics and research committee approval, a pretested structured questionnaire was administered to respondents by trained research assistants. Subjects were asked questions on number of crises, number of transfusions and number of hospitalizations in the previous one year

Results: Jos Centre had the highest frequency (30\%) of those who had more than three crises in the previous one year while Calabar (9.3\%) and Lagos (10\%) had the least. Frequency of more than three transfusions was highest in Maiduguri (6.3\%) and Abuja(6.3\%) respectively with Lagos, Enugu and Calabar centres in the southern part of Nigeria recording no transfusion during the study period. Calabar centre had the highest number of people (90.6\%) who had not been transfused before and those who had not been hospitalized (71.9\%). Maiduguri (16.7\%) and Jos (15\%) topped the number of those who had been hospitalized for more than three times while Lagos (0\%) and Calabar (3.1) had the least.

Conclusion: Altitude and hot weather are major environmental factors that contribute to the clinical severity of SCD in Nigeria. 
Abbreviations: SCA: Sickle Cell Anaemia; SCD: Sickle Cell Disease.

\section{Introduction}

Sickle cell anaemia (SCA) is the homozygous state of sickle cell disease (SCD). It is a chronic blood disorder characterized by red blood cells that assume an abnormal, rigid, sickle shape when deoxygenated [1]. Sickle cell haemoglobin is insoluble and forms crystals when exposed to low oxygen tension. This property is due to a single nucleotide change (thymine replaces adenine) in the $\beta$-globin gene leading to substitution of valine for glutamic acid at position 6 of the $\beta$-globin chain $[2,3]$. Following a vicious cycle of sickling and unsickling of the red cell, an irreversibly sickled red cell is formed which occludes small vessels producing ischaemia and pain in the vascular territory [4]. The prevalence of sickle cell disease in Nigeria is approximately $2 \%$ [5].

Sickle cell disease causes acute and chronic illness. The median life expectancy is reduced by at least 30 years in all countries, with greater reductions in low-income countries [6]. The clinical consequences can be divided into 4 groups: haemolysis and haematological complications, vaso-occlusion, infection, and organ dysfunction. These clinical consequences have a wide spectrum of severity with some patients having no symptoms and others suffering frequent, life-changing complications. Genetic, social and behavioral factors account for the variability in clinical severity [7]. These include co-inheritance of alpha-thalassaemia [8] and $\beta$ globin haplotypes- probably due to variations in haemoglobin level and foetal haemoglobin concentrations [9]. The Senegal haplotype is most benign, followed by the Benin, and the Central African Republic haplotype is the most severe form [10].

The rate of $\mathrm{HbS}$ polymerization is dependent on hypoxia, $\mathrm{pH}$, temperature and the hydration of red blood cells, all of which are potentially altered by environmental factors [6]. These environmental factors include climate, air quality, socio-economic status, exercise and infection [6].

The effects of weather vary with geography and most studies show that exposure to cold or wind increases hospital attendance with acute pain. It has been found that extremes of both hot and cold weather precipitate acute complications [11]. On exposure to cold, peripheral vasoconstriction occurs and the velocity of blood flowing through the vasculature of these areas is reduced [6]. This results in greater deoxygenation of blood in the peripheries, and red cells spending a longer period of time in the deoxygenated part of the circulation (Delay time). $\mathrm{HbS}$ polymerization therefore occurs more readily, and more rigid sickled red cells are produced which subsequently cause vaso-occlusion, presumably in tissues near to the areas exposed to cold [6]. Though less seasonal than temperature, wind speed also correlates with temperature, humidity and some air pollutants, which may explain some of the associations. This effect has been reproduced by many authors [12-14].

The association between daily variations in the level of urban air pollution and adverse health has been well documented though in the non-sickle population [15].

Most sickle cell disease patients live in low-income countries [6]. Therefore, socioeconomic factors are important determinants of health in all people. Numerous studies have shown that poverty is associated with worse health [16]. This is particularly relevant to SCD which is most prevalent in the poorest countries [17]. Exercise and physical activity are known to induce marked metabolic changes, including lactic acidosis, tissue hypoxia and dehydration, all of which predispose towards $\mathrm{HbS}$ polymerization and vaso-occlusion [6].

Nigeria has a vast land with differences in weather, with Southern areas being in a tropical climate and experiencing more rainfall and humidity than the North where it is typically more dry and can have temperatures rising to above $40^{\circ} \mathrm{C}$ [18]. These environmental factors vary in different geographical zones of Nigeria and may affect the severity of SCA as reflected by frequencies of crises, transfusions and hospitalizations in various zones. The present effort is aimed at comparing these parameters in six different geographical zones and the Federal Capital territory of Nigeria.

\section{Materials and Methods}

This is a multicentre cross-sectional observational study amongst sickle cell anaemia subjects, conducted in tertiary hospitals in the six geo-political zones of Nigeria- 
Lagos, Maiduguri, Enugu, Zaria, Jos, Calabar and Abuja, the Federal Capital Territory. Consenting respondents were recruited at each centre into the study after obtaining each institution's ethics and research committee approval. Options based questionnaire pretested for congruency and exclusion of ambiguities was administered on 261 (113 males and 148 females) respondents aged 18 years and above and to the parents or guardians of those below 18 years by trained research assistants.

Excluded in the study were participants on sickle cell disease modifiers such as hydroxyurea and those on chronic blood transfusion programs.

The questions asked were divided into three sections. In section one, the subjects were asked questions on their biodata such as age, sex, address, blood group etc. In section two, subjects were asked questions on number of crises (after the meaning of crisis had been explained to each subject as 'worsening change of symptoms and signs of sickle cell disease'), number of transfusions and number of hospitalizations in the preceding one year. Some of the questions asked in this section include: How many crises have you had in the last one year? Describe what happens on each occasion. How many times have you been transfused in the last one year?. How many pints of blood did you receive on each occasion? How many times have you been admitted into the hospital in the last one year?

\section{Results}

The age groups of the participants are presented in Table 1. The age group with the highest frequency was 18-27 years with a frequency of $42.9 \%$ (112 of 261). This was followed by the age group 28-37 years with a frequency of $24.3 \%$ (65 of 261). The age group with the least frequency was the age group 48 years and above.

\begin{tabular}{|c|c|c|c|c|c|c|c|c|}
\hline Age (years) & Lagos & Maiduguri & Abuja & Zaria & Jos & Enugu & Calabar & Total \\
\hline$<18$ & 12 & 8 & 14 & 4 & 3 & 0 & 5 & 46 \\
\hline $18-27$ & 1 & 21 & 13 & 26 & 21 & 14 & 16 & 112 \\
\hline $28-37$ & 4 & 8 & 12 & 13 & 13 & 6 & 9 & 65 \\
\hline $38-47$ & 1 & 7 & 8 & 4 & 1 & 3 & 2 & 26 \\
\hline$\geq 48$ & 2 & 4 & 1 & 3 & 2 & 0 & 0 & 12 \\
\hline Total & 20 & 48 & 48 & 50 & 40 & 23 & 32 & 261 \\
\hline
\end{tabular}

Table 1: Age of participants in each centre.

Participants other than the major tribes (Hausa, Igbo and Yoruba) had the highest frequency of $37.5 \%$ (98 of 261). This was followed by the major tribes- Hausa (26.8\%), Igbo (21.5\%) and Yoruba (14.2\%).

Table 2 shows the frequency of crisis across centres. When all centres were considered together, those who had not had crisis in the preceding one year had the highest frequency. For each centre, Calabar (75\%) and Lagos (50\%) centres topped the list of those who did not have crisis in the preceding one year while Jos (17.5\%) had the least frequency. Jos centre $(30 \%)$ had the highest frequency of those who had more than three crises in the preceding one year while Calabar (9.3\%) and Lagos $(10 \%)$ had the least frequencies.

\begin{tabular}{|c|c|c|c|c|c|c|c|c|}
\hline Crisis & Lagos & Abuja & Maiduguri & Zaria & Jos & Enugu & Calabar & Total \\
\hline Nil (\%) & $11(55.0)$ & $21(43.8)$ & $11(22.9)$ & $18(36.0)$ & $7(17.5)$ & $6(26.0)$ & $24(75.0)$ & $98(37.5)$ \\
\hline Once (\%) & $4(20.0)$ & $7(14.6)$ & $5(10.4)$ & $11(22.0)$ & $10(25.0)$ & $6(26.0)$ & $1(3.1)$ & $44(18.6)$ \\
\hline Twice (\%) & $2(10.0)$ & $2(4.2)$ & $10(20.8)$ & $7(14.0)$ & $5(12.5)$ & $4(17.4)$ & $3(9.3)$ & $33(12.6)$ \\
\hline Thrice (\%) & $1(5.0)$ & $6(12.5)$ & $10(20.8)$ & $4(8.0)$ & $6(15.0)$ & $2(8.7)$ & $1(3.1)$ & $30(11.50$ \\
\hline$\geq$ Thrice (\%) & $2(10.0)$ & $12(25.0)$ & $12(25.0)$ & $10(20.0)$ & $12(30.0)$ & $5(21.7)$ & $3(9.3)$ & $56(21.5)$ \\
\hline Total (\%) & $20(100)$ & $48(100)$ & $48(100)$ & $50(100)$ & $40(100)$ & $23(100)$ & $32(100)$ & $261(100)$ \\
\hline
\end{tabular}

Table 2: Number/Frequency of Crisis in One Year.

Table 3 shows the frequency of transfusion in the preceding one year. The frequency was highest in those who had not been transfused (55.9\%). Of those who had not been transfused, Calabar centre had the highest frequency (90.6\%). This was followed by Enugu (73.9\%) with Abuja having the lowest (41.7\%). Though the 
frequency of transfusion of more than three times is very low in all centres, there was a sharp difference between southern and northern centres with southern centres recording none in this category. In the north, frequency of more than three transfusions was highest in Maiduguri
(6.3\%) and Abuja (6.3\%). This was followed by Jos (5\%) and Zaria $(2 \%)$ while centres in the southern part of Nigeria- Lagos, Enugu and Calabar recorded none in the category of those who had more than three transfusions in the preceding one year.

\begin{tabular}{|c|c|c|c|c|c|c|c|c|}
\hline & Lagos & Maiduguri & Abuja & Zaria & Jos & Enugu & Calabar & Total \\
\hline Nil (\%) & $11(55)$ & $23(47.9)$ & $20(41.7)$ & $27(54.0)$ & $19(47.5)$ & $17(73.9)$ & $29(90.6)$ & $146(55.9)$ \\
\hline Once (\%) & $5(25.0)$ & $8(16.7)$ & $16(33.3)$ & $16(32.0)$ & $13(32.5)$ & $3(13.0)$ & $1(3.1)$ & $62(23.8)$ \\
\hline Twice (\%) & $3(15.0)$ & $7(14.6)$ & $5(10.4)$ & $4(8.0)$ & $4(10.0)$ & $1(4.3)$ & $1(3.1)$ & $25(9.6)$ \\
\hline Thrice (\%) & $1(5.0)$ & $7(14.6)$ & $4(8.3)$ & $2(4.0 \%)$ & $2(5.0)$ & $2(8.7)$ & $1(3.1)$ & $19(7.3)$ \\
\hline$>$ Thrice (\%) & $0(0)$ & $3(6.3)$ & $3(6.3)$ & $1(2.0)$ & $2(5.0)$ & $0(0)$ & $0(0)$ & $9(3.4)$ \\
\hline Total (\%) & $20(100)$ & $48(100)$ & $48(100)$ & $50(100)$ & $40(100)$ & $23(100)$ & $32(100)$ & $261(100)$ \\
\hline
\end{tabular}

Table 3: Number/Frequency of Transfusions in One Year.

Number/Frequency of hospitalization in the preceding one year is as shown in Table 4. The frequency of those who were not hospitalized was highest in Calabar centre (71.9\%) and least in Lagos centre (5\%). Maiduguri
$(16.7 \%)$ and Jos $(15 \%)$ topped the list of those who had been hospitalized for more than three times while Lagos $(0 \%)$ and Calabar had the least.

\begin{tabular}{|c|c|c|c|c|c|c|c|c|}
\hline & Lagos & Maiduguri & Abuja & Zaria & Jos & Enugu & Calabar & Total \\
\hline Nil (\%) & $1(5.0)$ & $16(33.3)$ & $16(33.3)$ & $21(42.0)$ & $11(27.5)$ & $9(39.1)$ & $23(71.9)$ & $97(37.2)$ \\
\hline Once (\%) & $4(20.0)$ & $17(35.4)$ & $12(25.0)$ & $16(32.0)$ & $18(45.0)$ & $7(30.4)$ & $3(9.4)$ & $77(29.5)$ \\
\hline Twice (\%) & $12(60.0)$ & $5(10.4)$ & $10(20.8)$ & $5(10.0)$ & $1(2.5)$ & $3(13.0)$ & $3(9.4)$ & $39(14.9)$ \\
\hline Thrice (\%) & $3(15.0)$ & $2(4.2)$ & $7(14.6)$ & $5(10.0)$ & $4(10.0)$ & $2(8.7)$ & $2(6.3)$ & $25(9.6)$ \\
\hline$>$ Thrice (\%) & $0(0)$ & $8(16.7)$ & $3(6.3)$ & $3(6.0)$ & $6(15.0)$ & $2(13.0)$ & $1(3.1)$ & $23(8.8)$ \\
\hline Total & $20(100)$ & $48(100)$ & $48(100)$ & $50(100)$ & $40(100)$ & $23(100)$ & $32(100)$ & $261(100)$ \\
\hline
\end{tabular}

Table 4: Number /Frequency of Hospitalization in One Year.

\section{Discussion}

Two best-characterized genetic modifiers of SCD are determinants of haemoglobin $\mathrm{F}$ (HbF) levels, [19] and the co-inheritance of alpha-thalassemia [8]. Disease severity is also related to $\beta$-globin haplotypes, probably due to variations in haemoglobin level and foetal haemoglobin concentrations. The Senegal haplotype is most benign, followed by the Benin haplotype, with the Central African Republic haplotype being the most severe form [10]. Environmental factors also play a prominent role in the clinical severity of SCD. This is because painful events occur as a result of ischaemic tissue injury and can be precipitated by hypoxia, dehydration, and extreme cold [7].

Generally, those who had not had crisis in the preceding one year constitute the majority in our study. However that the frequency of those who had more than three crises was highest in Jos centre and lowest in the Calabar $(9.3 \%)$ and Lagos (10\%) centres can be partly attributed to the effect of altitude on the clinical severity of this condition. Hypoxia can be caused by ascent to high altitude or when breathing mixture of gases with low oxygen content. The elevation of Jos, located on the Jos Plateau ranges from $1829 \mathrm{~m}$ to $2419 \mathrm{~m}$ above the sea level while Lagos and Calabar which are coastal cities are 0$45 \mathrm{~m}$ and $37-42 \mathrm{~m}$. This finding is in support of concerns about the adverse effects of high altitude on the clinical severity of SCD, principally because of the potential problems associated with low partial pressure of oxygen. The most frequently reported complication is acute splenic infarction in people with sickle cell trait, occurring both in aircraft and mountainous areas, particularly Denver, Colorado (altitude $1600 \mathrm{~m}$ ) [20]. Splenic sequestr ation has been reported in adults and children with HbSC disease on ascent to high altitude, including a report describing this complication in four children with HbSC disease who visited mountains at altitudes greater than $2700 \mathrm{~m}$. [21]. Vaso-occlusive complications have been associated with altitude in many studies [22,23]. In Saudi Arabia, authors found that the rate of acute vaso-occlusive 
complications in patients with SCD living in the highlands was about double that of lowlanders. They warned that patients with SCD should be cautious when visiting altitudes higher than $2000 \mathrm{~m}$.

The highest frequency (90.6\%) of those not transfused in the preceding one year in Calabar centre is in agreement with our earlier observation on frequency of crisis that was found to be low in Calabar. Though a similar finding may be expected in Lagos, this was not so. Inappropriate transfusion practice or possibly, more severe cases seen in Lagos than in Calabar might be responsible for this difference. Low transfusion rates $(<3$ times per year) recorded in all centres may be due to high level of care in the tertiary health centres where this study was carried out. However, a sharp division between North and South observed might be partly attributable to differences in weather in the two areas. Sahel or tropical dry climate is the predominant climate type in the northern part of Nigeria with annual rainfall lower compared to the southern part of Nigeria. The rainy season in the northern part of Nigeria lasts for only three to four months (June-September). The rest of the year is hot and dry with temperatures being as high as $40{ }^{\circ} \mathrm{C}$ $\left(104.0^{\circ} \mathrm{F}\right)$. Extreme heat can cause dehydration which can worsen the clinical severity of SCD in this region. We did not find a similar report with which to corroborate our findings.

The frequency of those who were not hospitalized was highest in Calabar centre and least in Lagos centre. One would have expected Lagos to follow the same pattern as Calabar in this category as observed in the number of crises and transfusions. Other factors, such as haplotypes, beyond the scope of this study, may be responsible. It could also be that patients with worse prognostic factors were being referred from other centres to Lagos centre than in Calabar. Other factors (genetic or otherwise) that may ameliorate the clinical severity of SCD in Calabar or worsen that of Lagos may also be responsible. For instance, Lagos being a commercial nerve centre of Nigeria with more industries than Calabar may have poorer air quality affecting their patients. According to Tewari, et al. most of the different air pollutants are closely interrelated, and increasing overall levels seem to correlate with increased hospital attendance, although higher concentrations of atmospheric carbon monoxide may offer some benefit for patients with sickle cell disease [6].

\section{Conclusion}

Altitude and hot weather are major environmental factors that contribute to the clinical severity of SCD in Nigeria. Air and water pollution in various cities may also induce gene mutations. These need to be studied.

We recommend that governments at all levels should make efforts to preserve the natural environment for a healthy friendly weather and climate. Desertification in Northern Nigeria should be reversed and halted to prevent its southwards expansion and the attendant health challenges.

Disclosure: The authors report no conflicts of interest in this work.

\section{References}

1. Olatundun OI (2010) Pathological basis of symptoms and crises in sickle cell disorder: implications for counseling and psychotherapy. Hematol Rep 2(1): e2.

2. Rees DC, Willims TN, Gladwin MT (2010) Sickle Cell disease. Lancet 376 (9757): 2018-2031.

3. Mousa SA, Qari MH (2010) Diagnosis and management of sickle cell disorders. Methods Mol Biol 663: 291-307.

4. De Montalembert M (2008) Management of Sickle cell disease. BMJ 337: 1397.

5. Akinyanju O (2009) National Burden of Sickle Cell Disorder and the way forward.

6. Tewari S, Brousse V, Piel FB, Menzel S, Rees DC (2015) Environmental determinants of severity in sickle cell disease. Haematologica 100(9): 1108-1116.

7. Robert J Thompson (2006) The Interaction of Social, Behavioral, and Genetic Factors in Sickle Cell Disease Genes, Behavior, and the Social Environment: Moving Beyond the Nature/Nurture Debate.

8. Higgs DR, Aldridge BE, Lamb J, Clegg JB, Weatherall DJ, et al. (1982) The interaction of alpha-thalassemia and homozygous sickle-cell disease. $\mathrm{N}$ Engl J Med 306(24): 1441-1446. 
9. Idowu Akinsheye, Abdulrahman Alsultan, Nadia Solovieff, Duyen Ngo, Clinton T Baldwin, et al. (2011) Fetal hemoglobin in sickle cell anemia. Blood 118(1): 19-27.

10. Ashley-Koch A, Yang Q, Olney RS (2000) Sickle hemoglobin ( $\mathrm{Hb} \mathrm{S}$ ) allele and sickle cell disease: A HuGE review. Am J Epidemiol 151(9): 839-845.

11. Adekile AD (2001) Sickle cell disease in Kuwait. Hemoglobin 25(2): 219-225.

12. Rogovik AL, Persaud J, Friedman JN, Kirby MA, Goldman RD (2011) Pediatric vasoocclusive crisis and weather conditions. J Emerg Med 41(5): 559-565.

13. Mekontso Dessap A, Contou D, Dandine-Roulland C, Hemery F, Habibi A, et al. (2014) Environmental influences on daily emergency admissions in sicklecell disease patients. Medicine (Baltimore) 93(29): e280.

14. Nolan VG, Zhang $Y$, Lash $T$, Sebastiani $P$, Steinberg $M H$ (2008) Association between wind speed and the occurrence of sickle cell acute painful episodes: results of a case-crossover study. $\mathrm{Br} \mathrm{J}$ Haematol 143(3): 433-438.

15. Spix C, Anderson HR, Schwartz J, Vigotti MA, LeTertre A, et al. (1998) Short-term effects of air pollution on hospital admissions of respiratory diseases in Europe: a quantitative summary of APHEA study results. Air Pollution and Health: a European Approach. Arch Environ Health 53(1): 54-64.
16. Marmot M (2005) Social determinants of health inequalities. Lancet 365(9464): 1099-1104.

17. Piel FB, Hay SI, Gupta S, Weatherall DJ, Williams TN (2013) Global burden of sickle cell anaemia in children under five, 2010-2050: modelling based on demographics, excess mortality, and interventions. PLoS Med 10(7): e1001484.

18. http://www.ripplesfoundationblog.com/2016/02/dif ferences-between-north-and-south-of.html\#

19. Menzel S, Thein SL (2009) Genetic architecture of hemoglobin F control. Curr Opin Hematol 16(3): 179186.

20. Goodman J, Hassell K, Irwin D, Witkowski EH, Nuss R (2014) The splenic syndrome in individuals with sickle cell trait. High Alt Med Biol 15(4): 468-471.

21. Githens JH, Gross GP, Eife RF, Wallner SF (1977) Splenic sequestration syndrome at mountain altitudes in sickle/hemoglobin C disease. J Pediatr 90(2): 203-206.

22. Mahony BS, Githens JH (1979) Sickling crises and altitude, Occurrence in the Colorado patient population. Clin Pediatr 18(7): 431-438.

23. Addae S, Adzaku F, Mohammed S, Annobil S (1990) Sickle cell disease in permanent residents of mountain and low altitudes in Saudi Arabia. Trop Geogr Med 42(4): 342-348. 